\title{
Comparison of Satellite Precipitation Products with Rain Gauge Data for the Khumb Region, Nepal Himalayas
}

\author{
Munehisa K. YAMAMOTO \\ Center for Environmental Remote Sensing, Chiba University, Chiba, Japan \\ Ken'ichi UENO \\ Graduate School of Life and Environmental Sciences, University of Tsukuba, Tsukuba, Japan \\ and \\ Kenji NAKAMURA \\ Hydrospheric Atmospheric Research Center, Nagoya University, Nagoya, Japan \\ (Manuscript received 2 September 2010, in final form 13 July 2011)
}

\begin{abstract}
Rain gauge data for the period of 1998-2004 from the Syangboche Automated Weather Station (S-AWS) site in the Nepal Himalayas were compared with multi-satellite precipitation products for the period of 2003-2005, employing several retrieval algorithms: the Tropical Rainfall Measuring Mission (TRMM) Multisatellite Precipitation Analysis (TMPA), the Climate Prediction Center (CPC) morphing algorithm (CMORPH), the Precipitation Estimation from Remote Sensing Information using an artificial neural network (PERSIANN), and the Global Satellite Mapping of Precipitation (GSMaP). All the products, except GSMaP, showed an increase in precipitation during the summer monsoon, in agreement with S-AWS. However, PERSIANN showed large differences with the observed values in winter and CMORPH had a tendency to overestimate precipitation in the pre- and post-monsoon seasons relative to S-AWS/TMPA. Summer monsoon precipitation showed an increase in the evening and mid-night in all products except GSMaP, but the local-time peak in PERSIANN lagged compared to that of S-AWS by several hours, and the peak in other products was ahead of that in S-AWS by several hours. All products except for PERSIANN showed an increase in precipitation during the morning. The differences among the products may reflect microwave signatures from convection, the sun-synchronous satellite orbit, and infrared-merging processes. A verification of rain detection by GSMaP revealed good scores over global land areas except for the Tibetan Plateau (including the present study area) due to insufficient resolution for rain/no-rain classification. The peak local-time distribution of precipitation showed a relationship with the topography in the order of precipitation radar (strongest relationship), microwave radiometer, and infrared products.
\end{abstract}

Corresponding author and present affiliation: Munehisa $\mathrm{K}$. Yamamoto, Graduate School of Science, Kyoto University, Kitashirakawa-oiwake, Sakyo, Kyoto 606-8502, Japan.

E-mail: mkyamamoto@kugi.kyoto-u.ac.jp

(c)2011, Meteorological Society of Japan

\section{Introduction}

The Nepal Himalayas consist of high mountains and deep valleys that produce abrupt diurnal variations in precipitation. Field observations by a dense rain-gauge network over a drainage area in the Khumbu Himal in 
the 1970s revealed that precipitation occurred mainly in the daytime (nighttime) around ridges (valley bottoms) (Ageta 1976). Since 1994, multiple automatic weather stations (AWSs) have been installed in the Khumb region to provide in situ precipitation data in high-elevation areas (e.g., Ueno et al. 1996; Tartari et al. 1998). One of the important characteristics of the precipitation record in this region is the nocturnal precipitation that occurs at lower elevations after the monsoon onset (Ueno et al. 2008). This precipitation is strongly linked to the modification of local circulation in deep valleys (Barros and Lang 2003).

Given the complex topography of the Himalayan region and a lack of rain-gauge networks, satellite measurements are a powerful tool for investigating the mechanisms of precipitation systems by estimating the areal precipitation amount over the entire Himalayas. To confirm the accuracy of satellite measurements, the data are generally compared with in situ measurements. For example, Barros et al. (2000) reported good agreement between satellite and observed data for $0.5 \mathrm{~mm} \mathrm{~h}^{-1}$ precipitation, although rain detection was worse at stations at higher elevations. Their study compared rain rates observed by the Tropical Rainfall Measuring Mission (TRMM) Precipitation Radar (PR) and the TRMM Microwave Imager (TMI) with that of AWSs over central Nepal during a monsoon season. Bookhagen and Burbank (2006) noted that the monthly or seasonal rainfall amounts from the combined PR-TMI product were significantly lower than the amounts measured by a gauge network in central Nepal, which they attributed to the infrequency of satellite measurements. Shrestha et al. (2011) also reported poorer performance with increasing altitude in terms of the rainfall amount and detection rate of Global Satellite Mapping of Precipitation (GSMaP) data compared with rain gauge observation data in Nepal. Although it is difficult to quantitatively estimate the precipitation amount over highland areas, previous studies have reported reasonable results from accumulated or snapshot data. For example, Bhatt and Nakamura (2005) compiled TRMM PR data and showed a nocturnal precipitation band along south-facing slopes in multiple valleys of the Himalayas. Based on a combined analysis of rain gauge data, sounding data, satellite overpass images, and reanalysis data for the Central Nepal area, Lang and Barros (2002) and Barros and Lang (2003) reported that moisture and unstable upslope flows were associated with heavy rainfall.

To reduce the uncertainty in rain estimates for hydrological applications, estimation techniques have been developed that merge multiple spaceborne sources
[PR, microwave (MW) radiometers, and infrared (IR) radiometers]. These include the TRMM MultiSatellite Precipitation Analysis (TMPA) (Huffman et al. 2007), the Climate Prediction Center (CPC) morphing (CMORPH) approach for high-resolution precipitation products (Joyce et al. 2004), Precipitation Estimation from Remote Sensing Information using an artificial neural network (PERSIANN) (Hsu et al. 1997), and GSMaP (Kubota et al. 2007; Aonashi et al. 2009; Ushio et al. 2009). These high-resolution precipitation products have been introduced and evaluated individually and collectively (e.g., Gebremichael and Hossain 2010). Previous studies have shown that these products are in good agreement with widespread rain-gauge network data for West Africa and China (Nicholson et al. 2003; Zhou et al. 2008); however, few studies have compared precipitation amount and characteristics in mountainous regions because of the difficulty of rainfall retrieval from MW radiometers and the sparse distribution of rain gauges in such regions.

This study aims to compare precipitation data retrieved from several products measured by satellite sensors with long-term in situ AWS data at high elevations in the Nepal Himalayas to investigate discrepancies at various time scales.

\section{Data}

We analyzed rain gauge data observed at Syangboche AWS from 1998 to $2004\left(86^{\circ} 43^{\prime} \mathrm{E}, 27^{\circ} 49^{\prime} \mathrm{N}, 3833 \mathrm{~m}\right.$ above sea level; hereafter S-AWS). S-AWS is situated in a V-shaped valley, as shown in Fig. 1. Precipitation was measured using a tipping bucket-type gauge without a heating system, and was recorded by a data logger at 30-minute intervals (20-minute intervals from September 2002). Precipitation is expected to have been liquid throughout the observation period because almost all the rain fell when surface temperatures were above $0^{\circ} \mathrm{C}$ at the altitude of S-AWS (Ueno et al. 2008). To assess the effect of altitude and topography (e.g., valleys or mountain ridges) on precipitation characteristics, such as the amount and diurnal variations, we considered the results presented by Tartari et al. (1998), who analyzed raingauge measurements at the Pyramid station $\left(86^{\circ} 49^{\prime} \mathrm{E}\right.$, $27^{\circ} 58^{\prime} \mathrm{N}, 5050 \mathrm{~m}$ above sea level) located at a higher altitude than S-AWS in a mountainous region.

We evaluated eight multi-satellite precipitation products that use four different retrieval algorithms. The first product is TMPA (hereafter 3B42), for which the 3B42 product uses combined MW, IR, and rain gauge data. 3B42 rain estimates are computed using the following four steps: 1) MW precipitation estimates, converted with the Goddard Profiling Algorithm (GPROF) (Kum- 
Table 1. Summary of multi-satellite data products used in this study.

\begin{tabular}{lcccccc}
\hline \multirow{2}{*}{ Product } & \multirow{2}{*}{ Version } & Horizontal & Temporal & & \multicolumn{3}{c}{ Input } \\
\cline { 5 - 8 } & & resolution & resolution & MW & IR & Gauge \\
\hline 3B42 & 6 & $0.25^{\circ}$ & $3 \mathrm{hrs}$ & $\mathrm{x}$ & $\mathrm{x}$ & $\mathrm{x}$ \\
cpccombMW & & $0.25^{\circ}$ & $3 \mathrm{hrs}$ & $\mathrm{x}$ & & \\
CMORPH & & $0.25^{\circ}$ & $3 \mathrm{hrs}$ & $\mathrm{x}$ & $\mathrm{x}$ & \\
PERSIANN & & $0.25^{\circ}$ & $3 \mathrm{hrs}$ & $\mathrm{x}$ & $\mathrm{x}$ & \\
GSMaP_MWR & 4.84 & $0.25^{\circ}$ & $1 \mathrm{hr}$ & $\mathrm{x}$ & & \\
GSMaP_MWR+ & 4.84 & $0.25^{\circ}$ & $1 \mathrm{hr}$ & $\mathrm{x}$ & & \\
GSMaP_MVK & 4.84 & $0.1^{\circ}$ & $1 \mathrm{hr}$ & $\mathrm{x}$ & $\mathrm{x}$ & \\
GSMaP_MVK+ & 4.84 & $0.1^{\circ}$ & $1 \mathrm{hr}$ & $\mathrm{x}$ & $\mathrm{x}$ & \\
\hline
\end{tabular}

merow et al. 2001) are inter-calibrated and combined; 2 ) IR precipitation estimates are calculated using the calibrated MW precipitation; 3) MW and IR estimates are combined; and 4) rain gauge data are integrated using a histogram-matching technique (Huffman et al. 2010).

The second product is CMORPH, which uses a motion vector algorithms using combined IR data that traces precipitation estimates from MW radiometer observations as an additional data source (cpccombMW). The third product is PERSIANN, for which the rain rate is based on combined IR data and estimated by a neural network technique that is trained and updated using the rain rate estimated from MW radiometers. The fourth is GSMaP, for which we consider GSMaP_MWR, GSMaP_MWR+, GSMaP_MVK, and GSMaP_MVK+. MWR represents precipitation estimates derived from MW radiometer data using a GSMaP retrieval algorithm (Kubota et al. 2007; Aonashi et al. 2009). MVK represents precipitation estimates derived from temporal interpolation of the MW radiometer product using the morphed technique, as well as CMORPH and a Kalman filter using geostationary IR data (Ushio et al. 2009). The symbol " + " in the product name denotes additional utilization of the National Oceanic and Atmospheric Administration (NOAA) Advanced Microwave Sounder Unit-B (AMSU-B) product (Ferraro et al. 2005).

Table 1 lists the combinations of input data sources (MW, IR, and rain gauges) for the various products. Because MW and IR data are combined in many of the satellite sensors [i.e., TMI, the Special Sensor Microwave Imager (SSM/I), the Advanced Microwave Scanning Radiometer for EOS (AMSR-E) and AMSU for MW; the Geostationary Operational Environment Satellite (GOES), the Geostationary Meteorological Satellite (GMS), the Multi-functional Transport Satellite (MTSAT), and Meteosat, maintained geostationary meteorological satellite by the European Organization for the Exploitation of Meteorological Satel- lites, for IR], we focus on the differences among the retrieval algorithms and the various combinations of input data sources. Data were compared for 2003-2005, over which period, all the products were available. We carried out the same analysis using 3B42 for 1998-2004 and 2003-2005, revealing only minor differences between the two periods. To compare satellite-retrieved precipitation amounts with S-AWS data, the nearest pixel to S-AWS was selected (squares in Fig. 1; domains for GSMaP_MVK and GSMaP_MVK+ differed from those of the other products because of the difference in horizontal resolution). Given the topography around S-AWS, the pixels covered ridges at high elevations.

Three-hourly time series (e.g., 0000, 0300, 0600; UTC $\pm 1: 30$ ), which is the same time resolution as 3B42, for precipitation amounts were also collocated with the horizontal resolutions of TRMM PR and TMI $\left(0.05^{\circ}\right.$ and $0.25^{\circ}$, respectively) for $1998-2004$ from the instantaneous surface rain rate derived from version 6 of PR 2A25 (Iguchi et al. 2000, 2009) and from TMI 2A12 (GPROF retrievals) (Kummerow et al. 2001; Olson et al. 2006; Wang et al. 2009). These TRMM products were never free from bias related to the local time of sampling (Negri et al. 2002). Hirose et al. (2008) reported that close to $80 \%$ of the Tibetan Plateau showed a significant peak in the diurnal signature for the 8 years of TRMM PR, based upon a $0.2^{\circ}$ grid scale (this domain includes S-AWS). The diurnal peak in precipitation (in local time) within the domain appeared to be consistent, even in the short-term (multiple year) data. Although the peak-time distributions yielded acceptable results, it is difficult to deal with the precipitation amounts. Therefore, in this study, we simply compared the distributions of diurnal variations in 3-hourly mean precipitation amount throughout the Nepal Himalaya. 


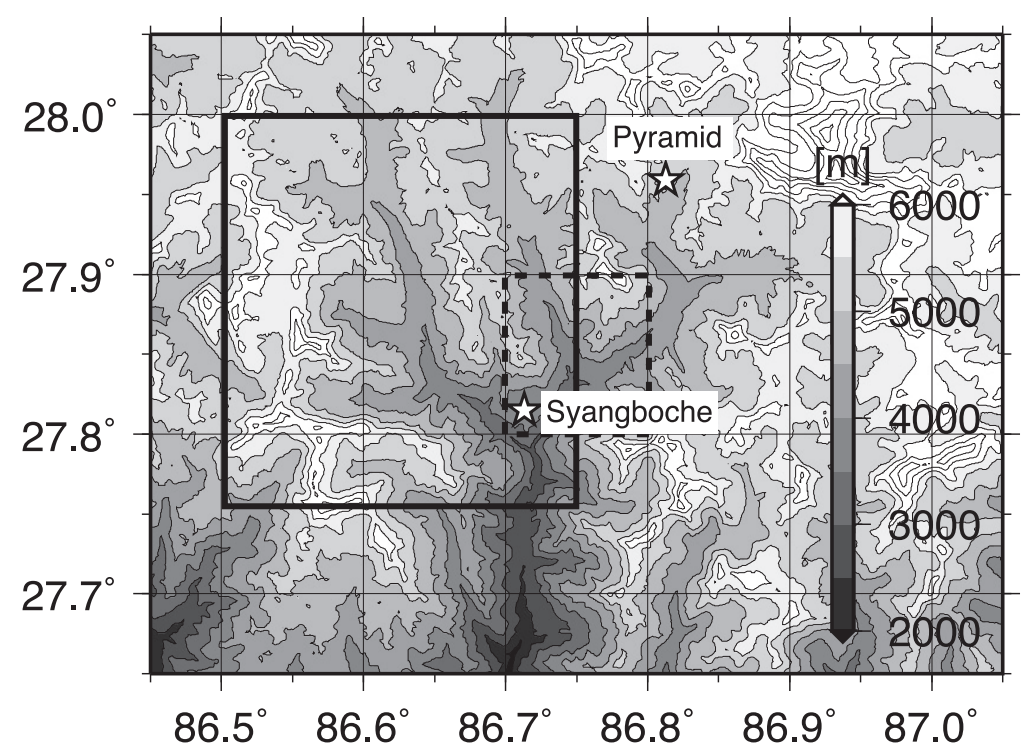

Fig. 1. Location of the Syangboche and Pyramid AWS sites. The dotted square shows the pixel selected for GSMaP_MVK and GSMaP_MVK+ products. The solid square shows that for the rest of the satellite precipitation products. The topography was contoured using the Shuttle Radar Topography Mission 90 m Digital Elevation Data Version 4 (Farr et al. 2007).

\section{Results}

\subsection{Seasonal changes}

Monthly mean precipitation obtained from S-AWS data for 1998-2004 and from satellite products for 2003-2005 are compared in Fig. 2. The S-AWS data show that most of the annual precipitation was concentrated from June to September, overlapping with the southwest monsoon period. This seasonal trend is also seen in the gauge data from the Pyramid AWS (Fig. 9 in Tartari et al. 1998), although with smaller amplitude than the S-AWS data. The seasonal variation in the $3 \mathrm{~B} 42$ product is consistent with the S-AWS data because the rain gauge data are merged into the 3B42 data. The PERSIANN product also showed enhanced rainfall in the monsoon season, but showed marked differences from S-AWS/3B42 for January-May, with a prominent peak in April. The cpccombMW and CMORPH products show a tendency to overestimate (underestimate) precipitation in the pre- and post-monsoon (inmonsoon) seasons compared with S-AWS. The GSMaP products did not show a clear increase in precipitation during the monsoon season. GSMaP_MVK and GSMaP_MVK+ showed a weak precipitation maximum in April.

To investigate the cause of the differences among the products, Fig. 3 shows a typical distribution of cloud and precipitation in the pre-monsoon season (0900 UTC on 29 April 2003). IR brightness temperature (Tbb) data are from Meteosat IR images provided by the globally merged full-resolution IR brightness temperature dataset (Janowiak et al. 2001). Cold clouds $(<240 \mathrm{~K}$ in Tbb) covered the region around S-AWS, in central Nepal $\left(28.0^{\circ} \mathrm{N}, 82.5^{\circ} \mathrm{E}\right)$ and western Nepal $\left(29.0^{\circ} \mathrm{N}\right.$, $\left.80.5^{\circ} \mathrm{E}\right)$. Precipitation is distributed over these areas in all the satellite precipitation products. Precipitation appeared frequently in central and western Nepal, corresponding to valley regions in the foothills of the Himalayas, as is typically observed. This result is indicative of orographic precipitation. CMORPH shows a larger precipitation area, as well as areas of weak precipitation (e.g., the Tibetan Plateau) compared with cpccombMW, reflecting the IR-merging process. Among all the products, the precipitation rate was highest, and the area of precipitation largest for PERSIANN, possibly because it is an IR-based product. In addition, the CMORPH algorithm performs a snow-screening process to discriminate between precipitation and snowice at the surface. This masking is not performed by PERSIANN; consequently, it tends to overestimate the precipitation amount, particularly in winter. The GSMaP_MWR and GSMaP_MWR+ algorithms did not detect precipitation in this area, and GSMaP_MVK and GSMaP_MVK+ detected weaker precipitation than did 


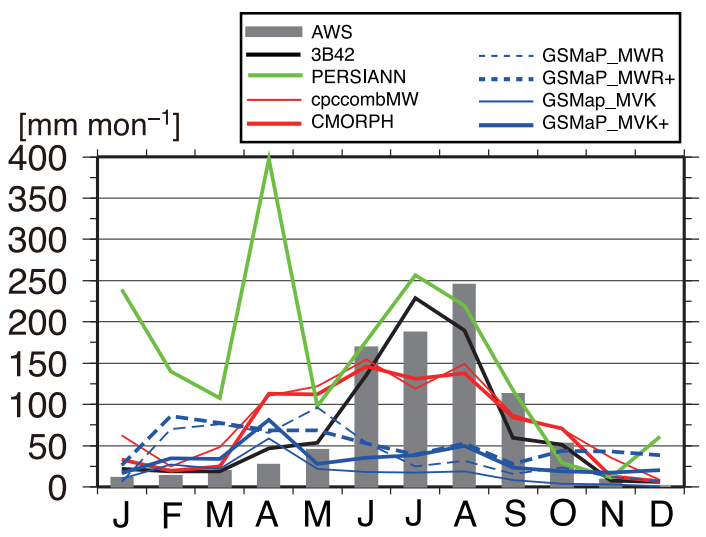

Fig. 2. Monthly mean precipitation amounts observed by the Syangboche AWS rain gauge (gray bars) in 1998-2004 and monthly mean precipitation at the nearest grid point from 3B42 (black line), PERSIANN (green line), cpccombMW (thin red line), CMORPH (thick red line), GSMaP_MWR (thin dotted blue line), GSMaP_MWR+(thick dotted blue line), GSMaP_MVK (thin solid blue line), and GSMaP_MVK+ (thick solid blue line) in 2003-2005.

the other satellite products.

To validate this detection deficiency for the GSMaP products, we focused on differences in the MW algorithms of GSMaP and GPROF with reference to TRMM PR. The surface rainfall rate for GSMaP_TMI and TMI 2A12, derived from MW brightness temperature measured by TRMM TMI, is compared with that for PR 2A25 over the period 1998-2004. The original TMI 2A12 and PR 2A25 data are fitted in the same grid for GSMaP_TMI (i.e., $0.25^{\circ} \times 0.25^{\circ}$ ). Following the verification method employed by Kubota et al. (2009) and Shrestha et al. (2011), all the events for each grid point are classified into a $2 \times 2$ contingency table, where $a$ is rain detected by both MW and PR estimates, $b$ is rain detected only by MW, $c$ is rain detected only by PR, and $d$ is no rain detected by MW or PR. We compared a number of indices between GSMaP and GPROF for MW-retrieved precipitation events, including the probability of detection (POD $=a /(a+c)$; an index of correct rainfall), the false-alarm ratio (FAR $=b /(a+b)$; an index of false rainfall), and the frequency bias (FB $=(a+b) /(a+c)$; an index of rainfall detection bias where $\mathrm{FB}=1$ indicates no bias). Figure 4 shows the horizontal distribution of POD, FAR, and FB during the monsoon season (June-September) over Nepal and the southern part of the Tibetan Plateau. The POD and FB scores for GSMaP_TMI over the foothill regions of the Himalayas (within southern Nepal as far as the border with India) were $>0.6$ and $\sim 1.0$, respectively, and superior to those of TMI 2A12. The FAR scores indicate that both products show minor amounts of false rainfall (the scores are generally less than 0.2). GSMaP_TMI shows superior performance over most land areas worldwide (data not shown). Over the Tibetan Plateau, POD and FAR values for GSMaP_TMI are generally similar to or slightly better than those for TMI 2A12, although large regional variations are apparent. The FB distributions show that TMI 2A12 under-detected (overdetected) precipitation in the east (west) of the Tibetan Plateau compared with PR. GSMaP_TMI did not detect precipitation over the entire Tibetan Plateau. In the region of the border between Nepal and Tibet, including the S-AWS site and areas with steep topography, the scores for GSMaP_TMI show a marked deterioration. For POD and FB, moreover, artificial gaps in the scores are apparent for a pixel size of $1^{\circ} \times 1^{\circ}$. This resolution corresponds to a no-rain brightness temperature database for the rain/no-rain classification (RNC) (Seto et al. 2005) in the GSMaP rain-retrieval algorithm. These results indicate the GSMaP algorithm is generally superior to GPROF for global land areas; however, the resolution of the current RNC should be enhanced to improve the scores for the southern slopes of the Himalayas and the Tibetan Plateau (e.g., a finer resolution could be employed for the RNC), as investigated in the present study.

As another possible cause of differences in seasonal variation in precipitation among the products may be deep convection with lightning activity during the premonsoon season in monsoon Asia (e.g., Hirose and Nakamura 2004; Kodama et al. 2005). At the S-AWS site, the frequency of high rate precipitation showed an increase in the pre-monsoon (March-April) and postmonsoon (October) seasons, and a large fraction of the total precipitation occurred in the monsoon season (Fig. 5). The satellite products also observed strong precipitation in the pre-monsoon season, indicating that deep convection causes pre- and post-monsoon increases in precipitation amount in the satellite products.

\subsection{Diurnal variation}

\section{a. Point comparison}

Figure 6a compares the satellite products and SAWS data in terms of diurnal variations in 3-hourly mean (e.g., 0000, 0300, 0600; UTC $\pm 1: 30$ ) precipitation amounts during the monsoon months (June- 

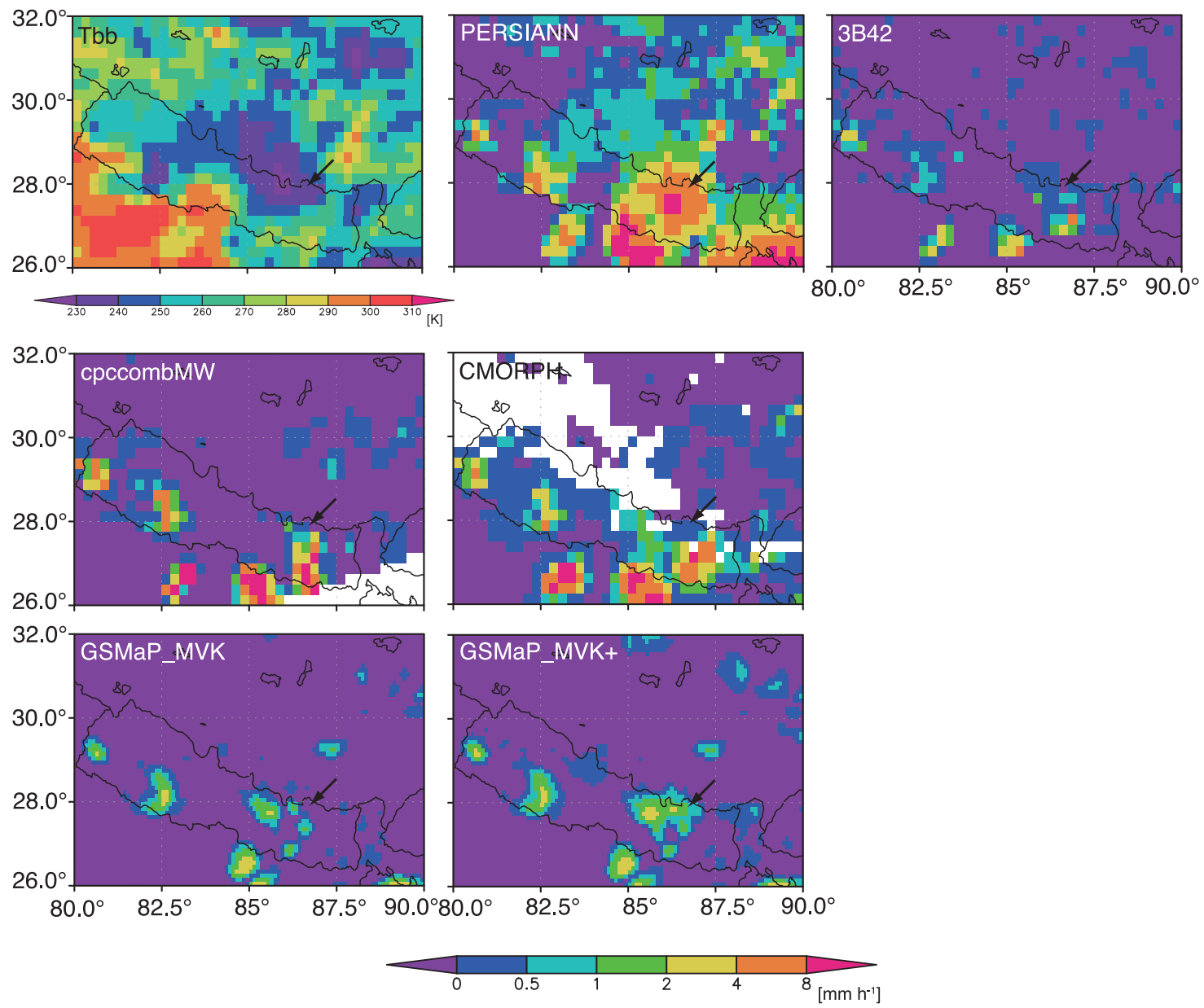

Fig. 3. IR brightness temperature observed by METEOSAT (labeled as Tbb) and hourly rain rate for PERSIANN, 3B42, cpccombMW, CMORPH, GSMaP_MVK, and GSMaP_MVK+ (labeled in each panel) at 0900 UTC on 29 April 2003. GSMaP_MWR and GSMaP_MWR+ did not show precipitation in this area. Arrows show the pixel closest to S-AWS. White pixels in cpccombMW and CMORPH indicate a lack of observation data and areas of snow cover, respectively.

September). Nepal Standard Time (NST) is 5 hours and 45 minutes ahead of Coordinated Universal Time (UTC) (herein, all times are given in NST). The S-AWS data show a precipitation maximum at nighttime, with a peak at around 23:45. All the products, except for GSMaP, also showed enhanced precipitation during the evening and nighttime. However, the local-time peak in PERSIANN lagged a few hours behind the peak observed at S-AWS, whereas the other products were a few hours ahead. Another difference from the S-AWS observations was increased precipitation in the morning (08:45), except for PERSIANN. The morning increase is especially marked for 3B42. All of the GSMaP products show similar diurnal variations to CMORPH, al- though with very small amplitude. The morning peak in the $3 \mathrm{~B} 42$ product consisted of low precipitation rates (e.g., $\sim 1-2 \mathrm{~mm} \mathrm{~h}^{-1}$ ), which are common during the monsoon season.

To assess whether the morning increase in precipitation for the satellite products (except PERSIANN) was caused by IR data, Fig. $6 \mathrm{~b}$ shows diurnal variations in average Tbb and the frequency of strong convection observed from METEOSAT IR images. The diurnal variations in Tbb show good correspondence to those in 3hourly mean precipitation amounts at S-AWS, but do not show a morning peak. We suggest two possible explanations for this result. First, the combined microwave estimates may have been affected by a sam- 
(a) POD (TMI2A12)

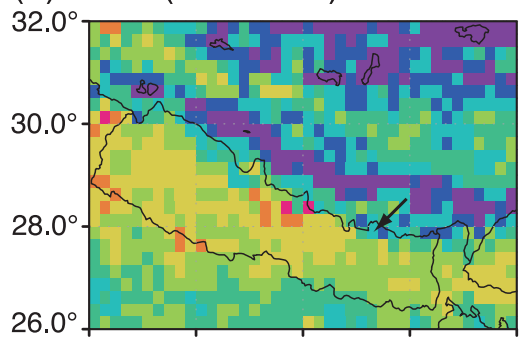

(d) POD (GSMaP_TMI)

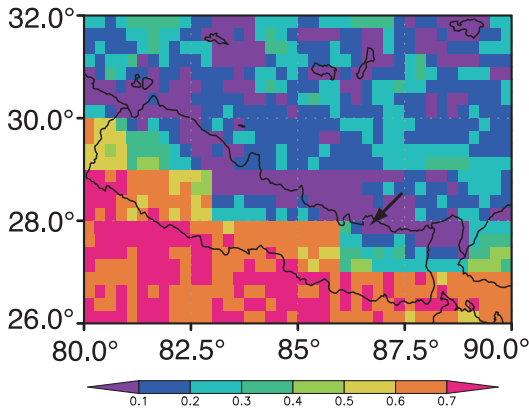

(b) FAR (TMI2A12)

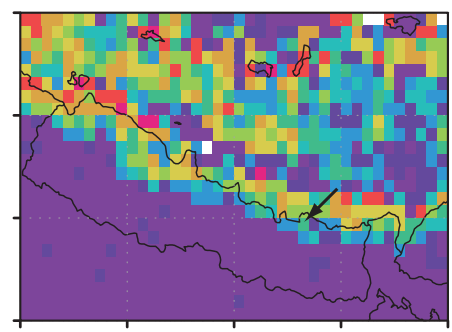

(e) FAR (GSMaP_TMI)

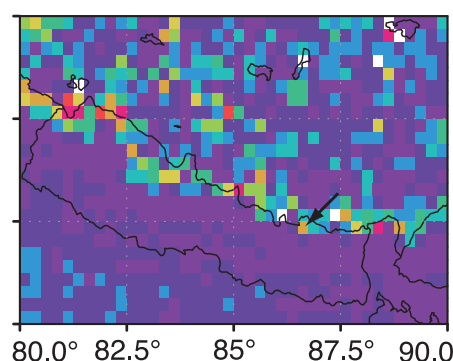

(c) FB (TMI2A12)

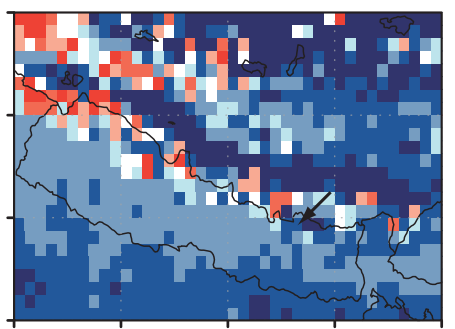

(f) FB (GSMaP_TMI)

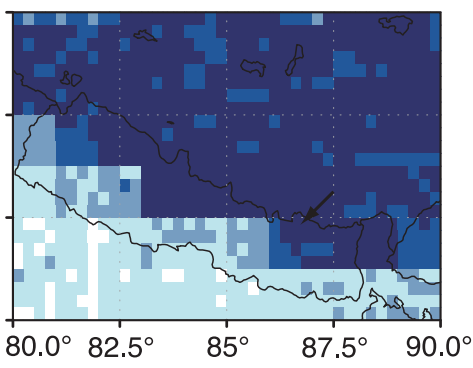

Fig. 4. Horizontal distributions of (a) POD, (b) FAR, and (c) FB for TMI 2A12, and (d-f) for GSMaP_TMI for JJAS 1998-2004.

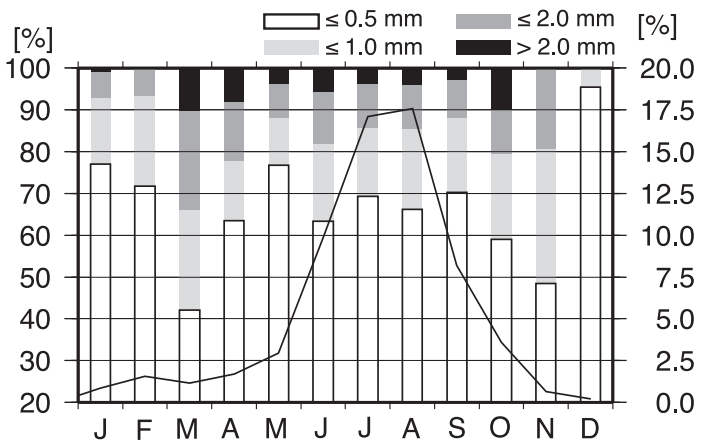

Fig. 5. Frequency of precipitation rates less than or equal to $0.5 \mathrm{~mm}, 1.0 \mathrm{~mm}$, and $2.0 \mathrm{~mm}$, and more than $2.0 \mathrm{~mm}$, per 30 -minute interval (20-minute interval from September 2002) under precipitation conditions (colored bars; left-hand scale) and fraction (\%) of precipitation count relative to the total log count (solid line; right-hand scale) measured at S-AWS.

pling problem. Huffman et al. (2010) showed the time history of the equator-crossing times of MW radiometers, revealing that the Sun-synchronous orbit of the SSM/I and AMSU series caused sampling times to be concentrated at around 6:00-10:00 and 18:00-22:00. In the case that an algorithm is sensitive to MW precipitation and/or contributes most of the MW precipitation for the product, the morning peak would be prominent, as in 3B42. This scenario explains why PERSIANN, which uses an IR-based algorithm, did not reproduce the morning increase in precipitation amount. Second, it is possible that S-AWS did not represent the satelliteobserved grid pixels. Tartari et al. (1998) reported that a close increment in morning precipitation was observed at the Pyramid AWS site (Fig. 2 in Tartari et al. 1998). The authors suggested that the peak probably correlated with local cumulus convection under the typical onset time of the valley breeze. Although the S-AWS data are consistent with the satellite products in terms of seasonal variation, the diurnal variations correspond to a higher altitude than the S-AWS site, such as the Pyramid AWS site.

\section{b. Regional comparison}

Figure 7 compares the distributions of peaks in diurnal variations among the satellite products (3-hour intervals) over all of Nepal and the southern part of the Tibetan Plateau. All of the products show a southward march of the peak local time from evening to morning. In the Himalayas (northern Nepal) and southern parts 


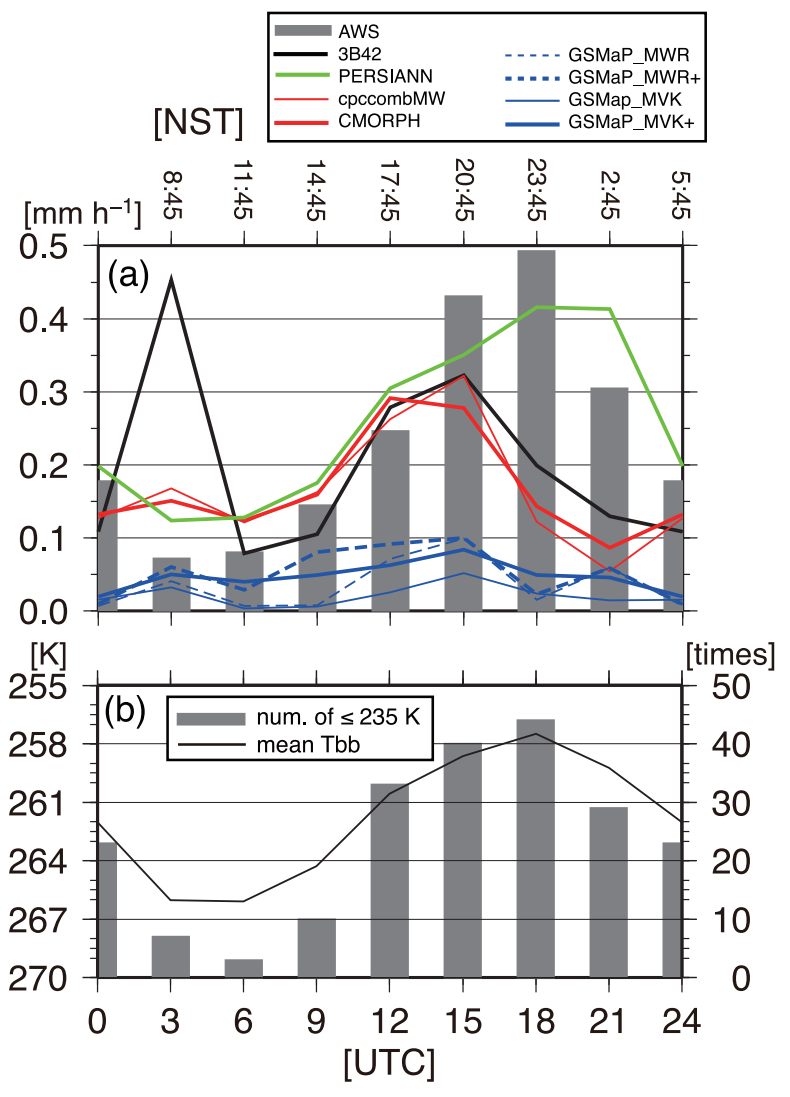

Fig. 6. (a) As for Fig. 2, but for 3-hourly mean values (time value on the upper abscissa \pm 1.5 hours) of precipitation amount in June-September (JJAS) during 1998-2004 (2003-2005) for S-AWS (satellite products) and (b) 3-hourly mean IR brightness temperature (solid line) and frequency less than $235 \mathrm{~K}$ (gray bars) observed by METEOSAT during JAS in 2000 and during JJAS in 2001-2004 (580 days).

of the Tibetan Plateau, most of the peaks occurred in the evening, toward midnight (17:45-23:45). A peak time at around 02:45 is dominant in the southern parts of Nepal, where elevations are lower. In 3B42 and all the GSMaP products, except GSMaP_MVK+, sporadic points indicate a signal at 08:45, as seen near $\mathrm{S}$ AWS (arrow). The pixels in the morning peak correspond to ridges on the topographic map. With few exceptions (e.g., S-AWS and southeastern Tibet at $29^{\circ} \mathrm{N}$, $88^{\circ} \mathrm{E}$ ), the peak times in the PERSIANN, CMORPH, GSMaP_MVK, and GSMaP_MVK+ products are later than those in the cpccombMW, GSMaP_MWR, and GSMaP_MWR+ products over the Tibetan Plateau.
The differences among these products are probably related to whether IR data were merged or not. Yamamoto et al. (2008) compared the timing of diurnal peaks retrieved by PR, TMI, and VIRS onboard the TRMM, revealing that globally, systematic shifts of a few hours were found in each sensor over land. The authors concluded that the IR radiometers detected deep convective clouds during the mature and decaying stages of the systems, while the TMI observed deep convection and solid hydrometeors during the mature stage. Compared with the IR-blended products, the IR effect would be stronger for the PERSIANN dataset. Their conclusions are consistent with the peak time lag for PERSIANN in the present study, as this product is based on IR-merged data.

\section{c. Pixel representativeness}

Figure 8 shows the distributions of TRMM PR and TMI peaks in local time. The peak time shift from the Tibetan Plateau in the early afternoon (11:45$17: 45)$ to the southern slopes of the Himalayas late at night (20:45-23:45) is clearer in the TMI data than in 3B42/PERSIANN/CMORPH data, particularly at night (23:45-05:45) for western and central Nepal $\left(28.5^{\circ}-29.0^{\circ} \mathrm{N}, 81.0^{\circ}-81.5^{\circ} \mathrm{E}\right.$ and $27.5^{\circ}-28.0^{\circ} \mathrm{N}$, $83.25^{\circ}-83.75^{\circ} \mathrm{E}$, respectively), where a basin and low mountain range extend along the border with India. These regional features are more detailed and pronounced in the PR products. A morning peak (08:45) was also found along the foothills of the Himalayas $\left(28.0^{\circ} \mathrm{N}, 80.0^{\circ} \mathrm{E}\right.$ and $\left.26.5^{\circ} \mathrm{N}, 84.0^{\circ} \mathrm{E}\right)$. Over the Tibetan Plateau, the peak time contrast from late morning (11:45) to evening (20:45) corresponds to the topography for PR, which is clearer than that for TMI.

Figure 9 shows the peak time distributions of PR at $0.05^{\circ}$ resolution for the Khumb region. The peak time depended on the local topography (e.g., valley vs. ridge). Focusing on the northern and northwestern part of the valley in which S-AWS is housed, an early morning (02:45) peak appears in the valley, while a late morning to early afternoon peak $(11: 45-14: 45)$ is seen along ridge tops. To confirm these differences in peak time, Fig. 10 shows differences in precipitation between daytime (09:15-17:15) and nighttime (17:15-01:15). It is clear that nighttime (daytime) precipitation is dominant within valleys (ridges), including the S-AWS site (Pyramid AWS site), with the exception of some pixels. As noted in the Introduction, surface observations show differences in diurnal peaks between valleys and ridges. Therefore, our result suggests that the PR product captures the ridge-and-valley-scale characteristics of diurnal variation, even though the diurnal variation is weak in each individual pixel, as shown in Fig. 6. 

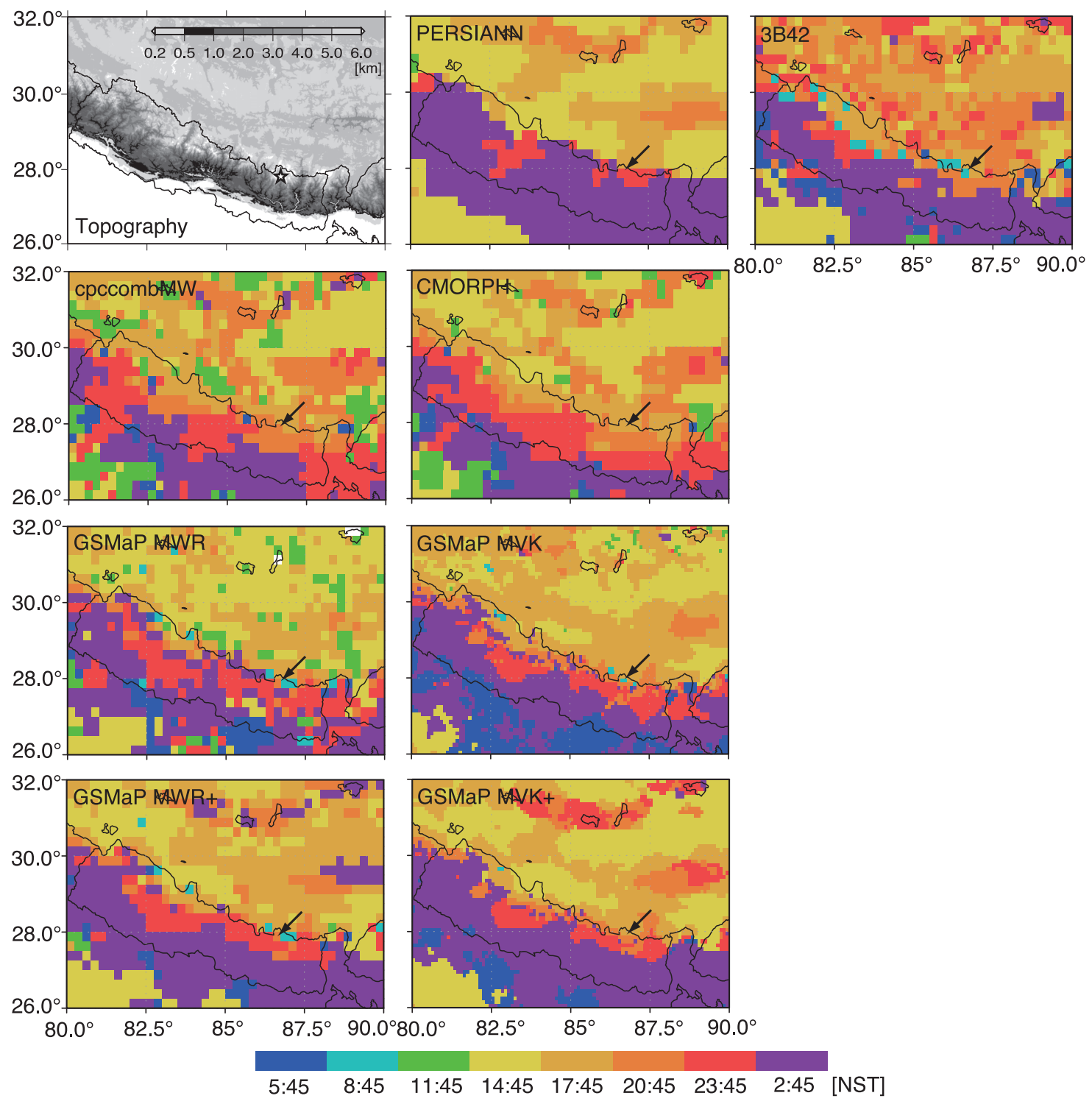

Fig. 7. Geophysical map contoured using the GTOPO30 product (labeled as Topography) and peak time of maximum precipitation amount for JJAS 2003-2005 derived from PERSIANN, 3B42, cpccombMW, CMORPH, GSMaP_MWR, GSMaP_MVK, GSMaP_MWR+, and GSMaP_MVK+ (labeled in each panel). Arrows show the pixel closest to $\mathrm{S}-\mathrm{AWS}$.

Diurnal variations in precipitation and convective cloud, as obtained from satellite data, have also been shown to be strongly affected by the topography of the Tibetan Plateau (Fujinami et al. 2005). Significant discrepancies between point precipitation and areal (grid) precipitation from satellite observations may reflect the representativeness of point precipitation. Therefore, the representativeness of point data should be carefully ex- amined.

The S-AWS data show a diurnal variation with a maximum at 23:45. The distributions of peak time derived from satellite observations indicate that the nighttime peak corresponds to the southern slopes of the Himalayas. Therefore, S-AWS may represent a lower altitude than the nearest grid points. However, the Pyramid AWS shows a secondary morning peak rather than a 


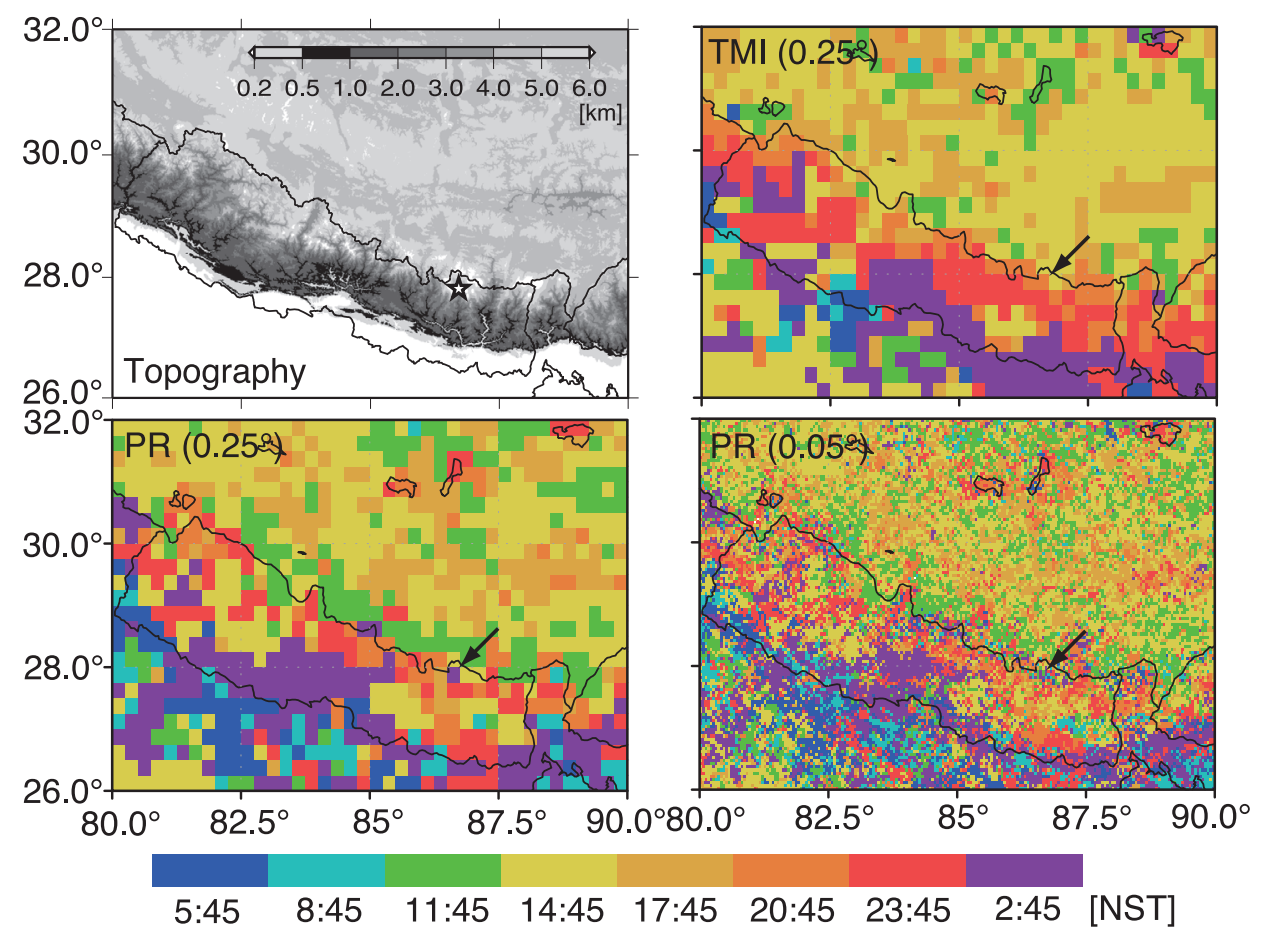

Fig. 8. As for Fig. 7, but for TMI at $0.25^{\circ}$ resolution and PR at $0.25^{\circ}$ resolution and $0.05^{\circ}$ resolution for JJAS in $1998-2004$.

nighttime peak. The distribution of peak times indicates that the Pyramid AWS represents mountainous regions and/or higher altitudes.

\section{Conclusions}

Seasonal and diurnal variations in precipitation observed at an AWS site in the Khumbu Himalayas were compared with those from the 3B42, PERSIANN, $\mathrm{CMORPH}$, and GSMaP products. Monthly mean precipitation in 3B42 corresponded to that in S-AWS throughout the year. Compared with S-AWS, PERSIANN showed a similar increase in precipitation during the monsoon season, but the rainfall amounts were overestimated in January-May, with a large increase in April. The CMORPH and cpccombMW products also showed enhanced precipitation during the monsoon season, but with a tendency to overestimate precipitation in the pre- and post-monsoon seasons. The GSMaP products did not show a clear increase in rainfall during the monsoon season. The GSMaP_MWR products showed a small increase in winter and spring, and the GSMaP_MVK products showed a precipitation maximum in April. The discrepancies among the products may reflect the IR-merging process and microwave retrieval from deep convection and orographic precipita- tion. Verification of the GSMaP algorithm revealed an underestimate for global land areas, possibly reflecting the resolution of the rain/no-rain classification in the algorithm.

Regarding the diurnal variation in precipitation during the monsoon season, all the products except for GSMaP showed an increase in precipitation from late evening to midnight, consistent with S-AWS. Relative to S-AWS, the maximum local-time peak was a few hours behind (ahead) in PERSIANN (3B42, cpccombMW, and CMORPH). These differences were found over the southern slopes of the Himalayas and the Tibetan Plateau. An additional peak appeared in the morning for all products except PERSIANN, possibly due to the fixed local time for observations of $\mathrm{SSM} / \mathrm{I}$ over the S-AWS or reflecting the representativeness of the selected pixel between satellite products and regional precipitation characteristics.

In Nepal and on the southern Tibetan Plateau, the southward march of the peak time from evening to early morning corresponded geographically to the slopes between the Tibetan Plateau and lowland areas. The distributions with merged IR data (GSMaP_MVK and CMORPH) were smoother than those without (GSMaP_MWR and cpccombMW), possibly due to 


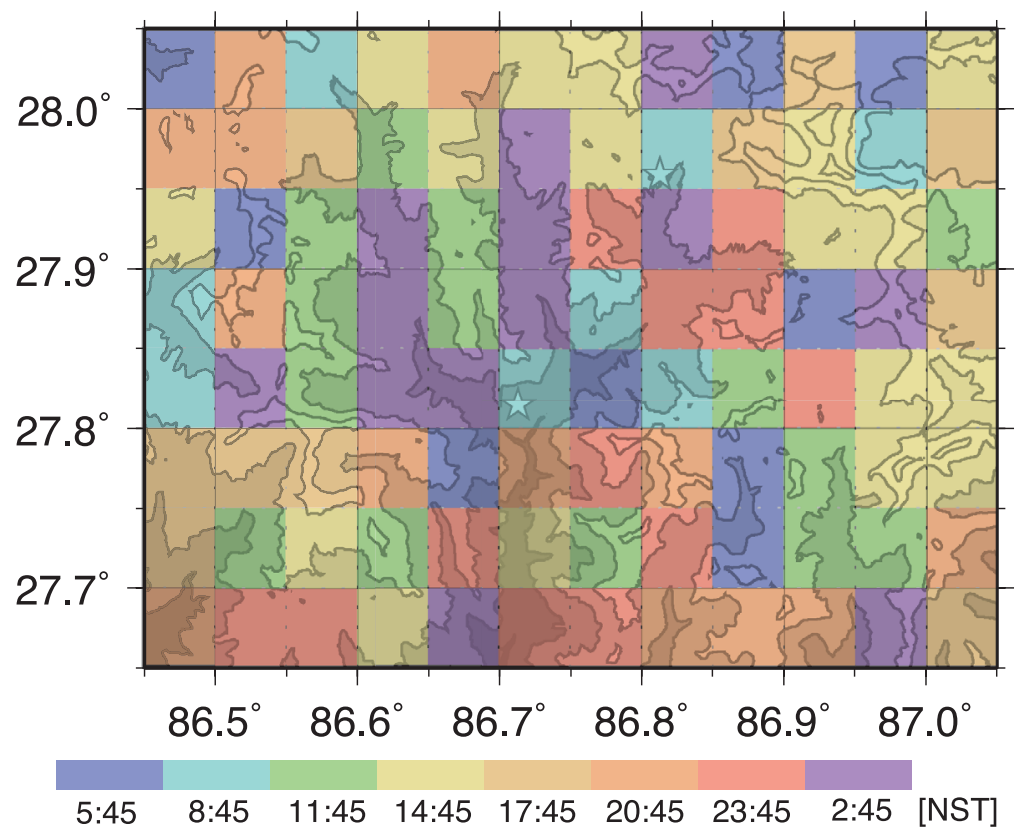

Fig. 9. As for PR $\left(0.05^{\circ}\right)$ in Fig. 8 (color overlay) and Fig. 1 (gray background), except for zooming in on the Khumb region.

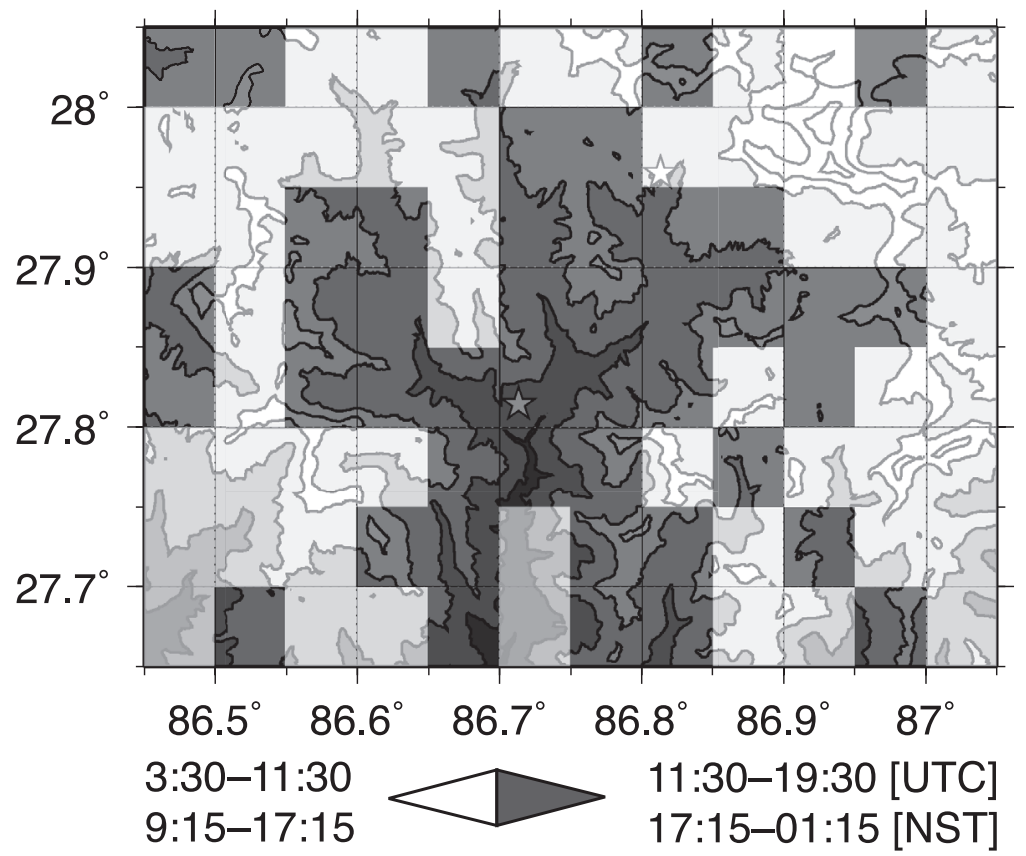

Fig. 10. Difference in precipitation amount between daytime (09:15-17:15 NST) and nighttime (17:15-01:15 NST) in JJAS 1998-2004, overlain on topography (gray background). Light (dark) colors indicate daytime-dominant (nighttime-dominant) pixels. 
continued high cloud-top heights until the decaying stage of the precipitation system. The peak local time for 3B42 represented finer topographic distributions over the Tibetan Plateau than that for PERSIANN, possibly due to the merging of rain gauge data.

Orographic differences (e.g., ridges versus valleys) were relatively pronounced for the TMI and PR products. Even at the scale of the Khumb valley, the nighttime (daytime) precipitation that was dominant over valley (ridge) regions was distinct in PR $\left(0.05^{\circ}\right)$. Thus, PR products capture the ridge-and-valley-scale characteristics of diurnal variation in precipitation, although the diurnal variation was weak for each individual pixel. The horizontal distribution of the peak in the diurnal variation indicated that $\mathrm{S}$-AWS represents the southern slopes of the Himalayas at relatively low altitudes.

As described above, there are two main issues to consider when comparing point and areal precipitation amounts, such as rain gauge and satellite products. The first problem is related to the algorithm employed to estimate rainfall. It is generally difficult to estimate precipitation precisely under conditions of weak, shallow, or isolated precipitation. This problem is pronounced over mountainous areas because of the increased altitude and high frequency of orographic precipitation. The second problem is horizontal resolution. Complex topography has a strong effect on the precipitation amount, as shown in the peak time differences of the present study. To overcome this problem requires field observations and further comparisons, considering topography and/or using a finer network of rain gauges to account for orographic effects. In a subsequent study, we intend to investigate how our results can be applied to other regions.

\section{Acknowledgements}

The authors appreciate helpful suggestions and comments by the journal editor and anonymous reviewers, which improved the manuscript. The TRMM products were provided by The National Aeronautics and Space Administration (NASA) and by the Japan Aerospace Exploration Agency (JAXA). S-AWS data were obtained from the Global Energy and Water Cycle Experiment (GEWEX) Asian Monsoon Experiment (GAME) of the Asian Automatic Weather Station Network Project (AAN), and archived in the Terrestrial Environment Research Center (TERC), University of Tsukuba, Japan (http://aan.suiri.tsukuba.ac.jp/). PERSIANN products were provided by the Center for Hydrometeorology and Remote Sensing, University of California, Irvine, USA. The CMORPH product was distributed by the CPC of the National Oceanic and Atmospheric Administration (NOAA)/National Weather Service. The GSMaP Project was sponsored by JSTCREST and is promoted by the JAXA Precipitation Measuring Mission (PMM) Science Team, and the GSMaP products were distributed by the Earth Observation Research Center (EORC), JAXA. Shuttle Radar Topography Mission (SRTM) data were provided by the National Geospatial-Intelligence Agency (NGA) and by NASA. GTOPO30 data were provided by the U.S. Geological Survey's EROS Data Center (for documentation, see http://www1.gsi.go.jp/geowww/globalmapgsi/gtopo30/README.html). This study was supported in part by the 21st Century COE Program "Dynamics of the Sun-Earth-Life Interactive System (SELIS)" of Nagoya University and by the "Formation of a Virtual Laboratory for Diagnosing the Earth's Climate System" program of the Ministry of Education, Culture, Sports, Science and Technology (MEXT), Japan.

\section{References}

Ageta, Y., 1976: Characteristics of precipitation during monsoon season in Khumbu Himal. Seppyo, 38(Special), 84-88.

Aonashi, K., J. Awaka, M. Hirose, T. Kozu, T. Kubota, G. Liu, S. Shige, S. Kida, S. Seto, N. Takahashi, and Y. N. Takayabu, 2009: GSMaP passive microwave precipitation retrieval algorithm: Algorithm description and validation. J. Meteor. Soc. Japan, 87A, 119-136.

Barros, A. P., M. Joshi, J. Putkonen, and D. W. Burbank, 2000: A study of the 1999 monsoon rainfall in a mountainous region in central Nepal using TRMM products and rain gauge observations. Geophys. Res. Lett., 27, 3683-3686.

Barros, A. P., and T. J. Lang, 2003: Monitoring the monsoon in the Himalayas: Observations in central Nepal, June 2001. Mon. Wea. Rev., 131, 1408-1427.

Bhatt, B. C., and K. Nakamura, 2005: Characteristics of monsoon rainfall around the Himalayas revealed by TRMM precipitation radar. Mon. Wea. Rev., 133, 149165.

Bookhagen, B., and D. W. Burbank, 2006: Topography, relief, and TRMM derived rainfall variations along the Himalaya. Geophys. Res. Lett., 33, L08405, doi:10.1029/2006GL026037.

Farr, T. G., P. A. Rosen, E. Caro, R. Crippen, R. Duren, S. Hensley, M. Kobrick, M. Paller, E. Rodriguez, L. Roth, D. Seal, S. Shaffer, J. Shimada, J. Umland, M. Werner, M. Oskin, D. Burbank, and D. Alsdorf, 2007: The shuttle Radar Topography Mission. Rev. Geophys., 45, RG2004, doi:10.1029/2005RG000183.

Ferraro, R. R., F. Weng, N. Grody, L. Zhao, H. Meng, C. Kongoli, P. Pellegrino, S. Qiu, and C. Dean, 2005: 
NOAA operational hydrological products derived from the AMSU. IEEE Trans. Geosci. Remote Sens., 43, 1036-1049.

Fujinami, H., S. Nomura, and T. Yasunari, 2005: Characteristics of diurnal variations in convection and precipitation over the southern Tibetan Plateau during summer. SOLA, 1, doi:10.2151/sola.2005-014.

Gebremichael, M., and F. Hossain (Eds.), 2010: Satellite rainfall applications for surface hydrology. Splinger, 327 pp.

Hirose, M., and K. Nakamura, 2004: Spatiotemporal variation of the vertical gradient of rainfall rate observed by the TRMM precipitation radar. J. Climate, 17, 33783397.

Hirose, M., R. Oki, S. Shimizu, M. Kachi, and T. Higashiuwatoko, 2008: Finescale diurnal rainfall statistics refined from eight years of TRMM PR data. $J$. Appl. Meteor. Climatol., 47, 544-561.

Hsu, K.-L., X. Gao, S. Sorooshian, and H. V. Gupta, 1997: Precipitation estimation from remotely sensed information using artificial neural networks. J. Appl. Meteor., 36, 1176-1190.

Huffman, G. J., R. F. Adler, D. T. Bolvin, G. Gu, E. J. Nelkin, K. P. Bowman, Y. Hong, E. F. Stocker, and D. B. Wolff, 2007: The TRMM Multisatellite Precipitation Analysis (TMPA): Quasi-global, multiyear, combined-sensor precipitation estimates at fine scales. J. Hydrometeor., 8, 38-55.

Huffman, G. J., R. F. Adler, D. T. Bolvin, and E. J. Nelkin, 2010: The TRMM Multi-Satellite Precipitation Analysis (TMPA). Satellite rainfall applications for surface hydrology. Splinger, 3-22.

Iguchi, T., T. Kozu, J. Kwiatkowski, R. Meneghini, J. Awaka, and K. Okamoto, 2009: Uncertainties in the rain profiling algorithm for the TRMM precipitation radar. J. Meteor. Soc. Japan, 87A, 1-30.

Iguchi, T., T. Kozu, R. Meneghini, J. Awaka, and K. Okamoto, 2000: Rain profiling algorithm for the TRMM precipitation radar. J. Appl. Meteor., 39, 20382052.

Janowiak, J. E., R. J. Joyce, and Y. Yarosh, 2001: A real-time global half hourly pixel-resolution infrared dataset and its applications. Bull. Amer. Meteor. Soc., 82, 205-217.

Joyce, R. J., J. E. Janowiak, P. A. Arkin, and P. Xie, 2004: CMORPH: A method that produces global precipitation estimates from passive microwave and infrared data at high spatial and temporal resolution. J. Hydrometeor., 5, 487-503.

Kodama, Y.-M., A. Ohta, M. Katsumata, S. Mori, S. Satoh, and H. Ueda, 2005: Seasonal transition of predominant precipitation type and lightning activity over tropical monsoon areas derived from TRMM observations. Geophys. Res. Lett., 32, L14710, doi:10.1029/2005GL022986.

Kubota, T., S. Shige, H. Hashizume, K. Aonashi, N.
Takahashi, S. Seto, M. Hirose, Y. N. Takayabu, K. Nakagawa, K. Iwanami, T. Ushio, M. Kachi, and K. Okamoto, 2007: Global Precipitation Map using Satelliteborne Microwave Radiometers by the GSMaP Project: Production and validation. IEEE Trans. Geosci. Remote Sens., 45, 2259-2275.

Kubota, T., T. Ushio, S. Shige, S. Kida, M. Kachi, and K. Okamoto, 2009: Verification of high-resolution satellite-based rainfall estimates around Japan using a gauge-calibrated ground-radar dataset. J. Meteor. Soc. Japan, 87A, 203-222.

Kummerow, C., Y. Hong, W. S. Olson, S. Yang, R. F. Adler, J. McCollum, R. Ferraro, G. Petty, D.-B. Shin, and T. T. Wilheit, 2001: The evolution of the Goddard Profiling Algorithm (GPROF) for rainfall estimation from passive microwave sensors. J. Appl. Meteor., 40, 18011820 .

Lang, T. J., and A. P. Barros, 2002: An investigation of the onsets of the 1999 and 2000 monsoons in central Nepal. Mon. Wea.Rev., 130, 1299-1316.

Negri, A. J., T. L. Bell, and L. Xu, 2002: Sampling of the diurnal cycle of precipitation using TRMM. J. Atmos. Oceanic Technol., 19, 1333-1344.

Nicholson, S. E., B. Some, J. McCollum, E. Nelkin, D. Klotter, Y. Berte, B. M. Diallo, I. Gaye, G. Kpabeba, O. Ndiaye, J. N. Noukpozounkou, M. M. Tanu, A. Thiam, and A. A. Toure, 2003: Validation of TRMM and other rainfall estimates with a high-density gauge dataset for West Africa. Part II: Validation of TRMM rainfall products. J. Appl. Meteor., 42, 1355-1368.

Olson, W. S., C. D. Kummerow, S. Yang, G. W. Petty, W.-K. Tao, T. L. Bell, S. A. Braun, Y. Wang, S. E. Lang, D. E. Johnson, and C. Chiu, 2006: Precipitation and latent heating distributions from satellite passive microwave radiometry. Part I: Improved method and uncertainties. J. Appl. Meteor. Climatol., 45, 702-720.

Seto, S., N. Takahashi, and T. Iguchi, 2005: Rain/no-rain classification methods for microwave radiometer observations over land using statistical information for brightness temperatures under no-rain conditions. $J$. Appl. Meteor., 44, 1243-1259.

Shrestha, M. S., K. Takara, T. Kubota, and S. R. Bajracharya, 2011: Verification of GSMaP rainfall estimates over the central Himalaya. Annual Journal of Hydraulic Engineering, JSCE, 55, 37-42.

Tartari, G., G. Verza, and L. Bertolami, 1998: Meteorological data at the Pyramid Observatory Laboratory (Khumbu Valley, Sagarmatha National Park, Nepal). Mem. Ist. ital. Idrobiol., 57, 23-40.

Ueno, K., H. Iida, H. Yabuki, K. Seko, G. S. Lhakupa, R. Kayastha, A. P. Pokhrel, M. L. Shrestha, T. Yasunari, and M. Nakawo, 1996: Establishment of the GEN Automatic Weather Station (AWS) in Khumb Region, Nepal Himalayas. Bull. Glacier Res., 14, 13-22.

Ueno, K., K. Toyotsu, L. Bertolani, and G. Tartari, 2008: Stepwise onset of monsoon weather observed in the 
Nepal Himalaya. Mon. Wea. Rev., 136, 2507-2522.

Ushio, T., K. Sasashige, T. Kubota, S. Shige, K. Okamoto, K. Aonashi, T. Inoue, N. Takahashi, T. Iguchi, M. Kachi, R. Oki, T. Morimoto, and Z. Kawasaki, 2009: A Kalman filter approach to the Global Satellite Mapping of Precipitation (GSMaP) from combined passive microwave and infrared radiometric data. J. Meteor. Soc. Japan, 87A, 137-151.

Wang, N.-Y., C. Liu, R. Ferraro, D. Wolef, E. Zipser, and C. Kummerow, 2009: TRMM 2A12 land precipitation product-Status and future plans. J. Meteor. Soc.
Japan, 87A, 237-253.

Yamamoto, M. K., F. A. Furuzawa, A. Higuchi, and K. Nakamura, 2008: Comparison of diurnal variations in precipitation system observed by TRMM PR, TMI, and VIRS. J. Climate, 21, 4011-4028.

Zhou, T., R. Yu, H. Chen, A. Dai, and Y. Pan, 2008: Summer precipitation frequency, intensity, and diurnal cycle over China: A comparison of satellite data with rain gauge observations. J. Climate, 21, 3997-4010. 